\title{
The Suggestion of Improving the Construction of the Co-operative
} Education Archives

\author{
Chaohua Deng ${ }^{1, a}$, Jie $\mathrm{Li}^{2, \mathrm{~b}}$ and Shuiying Wang ${ }^{3, \mathrm{c}}$ \\ ${ }^{1}$ Archives, Jingdezhen Ceramics University, Jiangxi 343003, China; \\ ${ }^{2}$ Material Science and Engineering institute, Jingdezhen Ceramics University, Jiangxi 343003, \\ China; \\ ${ }^{3}$ Archives, Jingdezhen Ceramics University, Jiangxi 343003, China; \\ a490355887@qq.com, blj7242@qq.com, ${ }^{c} 1459087023 @ q q . c o m$
}

\begin{abstract}
Co-operative education is common teaching mode in colleges or universities which has science or engineering professional. Through co-operative, students can complement and perfect the knowledge structure, the problems that the internship becomes a mere formality which in the colleges or universities can also be solved. Co-operative education can enhance students' chance. They apply theory knowledge that they have learned to practice, improving operation skills, enhancing the ability to communicate with people, dealing with emergency response capacity in the work. Establish archives for co-operative education teaching can promote the higher education management research and develop the connotation of this model, which can develop its strengths and circumvent its weaknesses.
\end{abstract}

Keywords: Co-Operative; Education; Archives; Construction

\section{完善产学合作教育教学档案建设的思考}

\author{
邓超华 ${ }^{1}$ ，李杰 ${ }^{2}$ ，汪水英 ${ }^{3}$ \\ 1 景德镇陶瓷大学档案馆, 江西省景德镇 333403 \\ 2 景德镇陶瓷大学材料科学与工程学院, 江西景德镇, 333403 \\ 3 景德镇陶瓷大学档案馆, 江西景德镇, 333403
}

摘要: 产学合作教育是含有理工科专业高等院校的常见教学模式, 通过产学合作, 学生的知识结构得 到补充和完善, 可以解决一些行业院校的学生实习流于形式的问题。产学合作教育可以增强学生动手的 机会, 使他们把象牙塔学到的理论知识运用到工作实际, 提升操作技能, 增强与人沟通的能力、工作中 处理紧急事件的应对能力。建立产学合作教育教学档案, 可以促进高等教育管理者不断研究、发展这种 教育模式的内涵, 使产学合作的教育活动能够扬长避短。

关键词: 产学合作; 教育教学; 档案; 建设

引言

产学合作教育是指高等学校与企业一起合作培养人才的一种教育模式。高等学校通过 与企业的合作, 不仅能发现最近的学术研究前沿和技术前沿, 还能获得一些企业的资金以 资助学生的学业发展, 更关键的是能使学生的理论知识的学习有实践的机会, 增强学生的 实践能力。所以产学合作教育, 从高校的角度上来讲, 有利于打破闭环的办学格局, 有利 于及时捕捉企业的准研究课题, 提高院校的自主创新能力, 有利于通过堂学习与实际工作 相结合, 培养高级应用型人才; 有利于增强学生的社会适应能力, 增强就业竞争力。企业 通过与大学的合作, 能积蓄基础技术、发现新的技术生长点、发展技术, 确保最新信息源, 
还能发现有用的技术人才做好人才储备。产学合作教育模式对于高等学校和企业来讲, 是 互惠互利的。产学合作教育的效果主要体现在其实现了教育与市场之间、大学人才和企业 人才之间的联合, 不仅为经济的发展带来中现实的效应, 也为人才培养起到了重要的作用。 建立产学合作教育档案, 有利于教育管理者今天更好研究这种教育模式, 提升产学合作教 育质量。

\section{1 产学合作教育档案的内容构成}

《高等学校档案管理办法》中所指的高等学校档案, 是指高等学校从事招生、教学、 科研、管理等活动直接形成的对学生、学校和社会有保存价值的各种文字、图表、声像等 不同形式、载体的历史记录。产学合作教育模式作为教育的一种重要形式, 也应当有属于 自己的专业档案。按照《高等学校档案管理办法》第三章的规定, 高校的教学类档案主要 包含以下内容: 主要包括反映教学管理、教学实践和教学研究等活动的文件材料。按原国 家教委、国家档案局发布的《高等学校教学文件材料归档范围》( (87) 教办字 016 号) 的相 关规定执行。为了保证产学合作教育的顺利进行以及产学合作教育的质量, 产学合作教育 档案的内容应该包含以教学实习、生产实习方面的材料：教学实习、生产实习的计划、大纲、 总结、实习指导书、实习讲义、实习结果鉴定, 有代表性的实习报告等。

\section{2 建立产学合作教育档案的意义}

\section{1 产学合作教育档案是教学档案的重要组成部分}

教学哲学是 “教和学的关系的哲学, 主要回答为何教和学、教学什么、如何教和学等问题”。教学从 内容上来说, 包含理论课的学习也包含实践环节的学习。很多工科院校在八十年代就已经慢慢开展 了产学合作这种教育模式, 教的主体是学生, 教师是教学的主导。产学合作教育的主要内容是侧重于 实践环节的教学, 目的是在教学过程中让学生把理论运用于实践, 锻炼自身的操作技能。因此产学合作教 育的档案是教学档案的重要组成部分。

\section{2 产学合作教育档案是评价教师的主要依据之一}

产学合作教育档案, 是全面评价教师的主要依据之一。“教师评价是根据学校的教育目标和教师的工 作任务, 运用恰当的评价理论和方法手段对教师个体的工作进行价值判断。” ${ }^{[2]}$ 然而, 当前教师教学评价 中存在诸多弊端和局限性。这主要表现在: 第一, 唯分数论。第二, 重结果, 第三, 评价标准不合理, 一 刀切。 ${ }^{[3]}$ 结果造成了某些教师的不公平感。实际上, 教师的教学能力是多方面的, “教师的教学能力有三 种成分构成: 教学认知能力、教学操作能力和教学监控能力。” ${ }^{[4]}$ 大学的教师, 有的是担任理论课的教学, 有的是担任实践教学, 更多的教学精力在于指导即将毕业的、在企业实习的学生。对于这类老师来讲, 评 判其能力的依据如果只是单纯的以分数而论, 就不能全面反映一个教师的教学能力和水平。而产学合作教 育档案对于实践课程教学的老师的评价, 可以使教育管理者对于教师的评价有更全面的认识。

\section{3 研究产学合作教育档案可以促进教学改革研究和教学方式的更新}

保障教学质量, 提高教学水平是高校一直在呼吁并提倡的, 高等教育培育的人才是直接要面向社会市 场, 因此高等教育的知识知识内涵和课程体系是在不断更新和发展的。而产学合作教育教学档案的内容, 既能体现学生在高校学习理论课的内容, 又能反映学生在企业实践学习中的内容。教学内容能否与市场紧 
密联系且保证不脱节, 可以通过产学合作的教学来反映, 因此研究产学合作教育档案可以为高校内教学改 革提供依据, 并促进教学方式更加契合市场, 与社会紧密联系。

\section{4 产学合作教育档案是本科教学评估的重要内容和依据}

高校本科教学评估已经成为国家宏观调控高等教育质量的一种重要手段。国家规定的《普通高等学校 本科教学工作审核评估范围》当中的一级指标第二项是 “师资队伍” , 下设的二级指标有分别是 (1) 数 量与结构;（2）教学水平;（3）教学投入;（4）教师发展与服务。其中教师队伍结构包含理论课教师队伍 的建设, 也包含实践型教师队伍及双师型教师队伍的建设。第四项 “培养过程” , 下设二级指标含有 “实 践教学” 的内容, 其评价的细化指标包含的内容实践教学体系建设、实习实训、社会实践及效果。工科院 校可以依据国家本科评估的要求整合产学合作教育档案, 并为评估提供可靠的依据。

\section{3 产学合作教育档案建设的现状及原因分析}

\section{1 产学研合作教育档案建设的现状}

建立产学合作教育档案是教学档案的重要组成部分, 他对于促进高校的专业内容与学生的职业能力对接有 举足轻重的作用。可以为评价教师的专业发展能力提供依据、促进教学内容的改革和教学手段的更新, 可 教育教学以及企业的发展都有重要的意义。但是遗憾的是, 产学合作教育的教学档案建设却不完整、不规 范、不科学, 管理手段落后。

\section{2 产学合作教育档案质量有待完善的原因分析}

\section{2.1 高校管理者的档案意识不强, 档案机构设置不到位, 人员配备不齐全。}

高等学校是一个职能多元化的机构。以人才培养、科学研究、社会服务为主要责任。管理重心也主要 在这三大块。

因为没有意识到产学合作教育档案对于教育教学的评价作用、研究作用, 没有长远的档案意识。因此没有 形成自上而下的关心、重视档案工作的氛围。

依据《高等学校档案管理办法》第六章第六条规定, 具备以下三个条件之一的高校应当设立档案馆:

（1）建校历史在 50 年以上的;（2）全日制在校生规模在 1 万人以上的;（3）已集中保管的档案资料在 3 万卷以上的。虽然很多高校已经满足了以上条件之一, 但是因为没有独立的档案管理场所和专业的档案管 理人员, 档案管理人员普遍是非专业化的构成, 基本没有专业化的关于档案管理的知识和技能。有的是由 普遍学历不高的教学辅助人员担任。有的是教学秘书兼任, 对于档案工作没有高度责任感, 缺乏耐心、细 致的工作态度, 所以产学合作教育的管理不科学、不规范。

\subsection{2 教师的对于产学合作教育的教学态度影响教学档案质量}

教师对于产学合作教育的态度会深刻影响教学档案的内涵、质量水准及收集整理速度。所谓教学态度 是指 “教师在深刻理解教学的价值、意义的基础上, 对教学形成的倾向和意愿” ${ }^{[5]}$ 假如教师对于产学合作 教育的态度不端正, 在教学中形成了一贯的以理论教学为主, 实践教学只是一种辅助教学, 可有可无, 对 于学生的实习指导以一种观望的态度, 对于产学合作教育的档案制作以一种敷衍的态度, 这样不仅会影响 产学合作教育档案制作的质量水平, 也会严重影响到该档案归档时间。

\section{2.3 档案管理跨度大, 缺乏制度性保障}

产学合作教育教学档案的形成涉及几个部门。一般是高等学校教务处的实践教学管理部门负责与企业 
洽谈合作事宜, 所以与企业合作的产学合作意向书或者合同书，一般是由教务处负有管理责任。由本校的 教师或者企业的一线实践教学指导老师负责教学实习、生产实习的计划、实习大纲、实习指导书、实习讲 义等的形成, 由教学院系负责档案内容的质量监控; 针对学生的有实习结果鉴定、实习总结、实习报告等 是主要是由学生实习所在的企业进行评定。但是归档以及立卷工作主要是由高校的教学院系负责。产学合 作教学档案的多头管理, 容易造成管理的混乱。以及相互推诿责任。所以没有建立独立的档案馆的高校, 一旦要进行教学评估, 就要召开多个部门的材料收集整理的推进会。

有的高校由于受到传统思维的影响, 和体制不健全, 教学档案管理不到位, 还存在无制度不规范、有制 度无落实、有检查无纠错等现象 ${ }^{[6]}$, 从领导层和具体的工作人员, 都没有认识到产学合作教育档案的收集、 整理工作的重要性, 工作比较随意, 教学档案应有的地位和作用仍未得到充分肯定和体现。

\subsection{4 产学合作教育教学档案的信息化管理水平低}

信息技术的飞速发展，为教学档案的管理带来了便捷。计算机的存储容量大。传统的 纸质材料进行扫面等信息化处理后, 便于检索、查询、借阅。还可以把产学合作教育的现 场资料录制成声形并茂的影响资料进行保存。使得教学档案更加形象生动, 便于进行教学 研究, 促进今后的教学改革。但是由于受高校的管理者、教师的档案意识不强, 管理幅度 大等因素的影响, 高校产学合租教育档案的信息化水平普遍偏低。

\section{4 完善产学研合作教育档案建设的建议}

\section{1 增强高校管理者档案意识, 建立专业教学档案室, 落实人员编制保障}

强化高等教育管理者的档案意识, 从意识和观念形态上来看, 首先是提高对教学价值 的认识, 态度上重视教学档案, 树立教学档案管理的新理念。 ${ }^{[7]}$ 将档案工作纳入学校整体 发展规划, 设立档案建设的专项管理经费, 保障档案建设经费的稳定投入。建立专业的教 学档案室, 在教学档案室以教学院系为单位、或者以专业课程为单位设立专门的产学合作 教育档案库。落实档案整理、查询利用所需要的电脑、复印、扫描等专用设备。分管档案 的校级领导应有忧患意识, 为保证档案的安全管理优化教学档案库房建设。严格按照国家 管理档案的规定, 购置坚固的防火专用档案柜, 在库房配备防盗门、防盗窗。

为教学档案的管理配备专门的管理人员, 为保持档案管理队伍的相对稳定, 采取一切 措施, 加大对档案馆员的政治和业务培训的频率。在工作中彰显人文关怀, 档案馆员的待 遇与教学、科研人员一样享有评定职称的权益。做好档案馆员的专业技术职务的聘任工作。 并且按照相关文件的规定, 对于长期接触有毒有害物质的档案工作人员建立职业保障和补 助。

\section{2 端正教师的对于产学合作教育的教学态度, 保障产学教育档案的质量}

产学合作教育的一线教师, 是教学档案形成的主要参与者。只有教师有严谨的教学态 度, 才会有高质量的产学合作教育档案。因此, 要强化一线产学教育教师的档案意识。让 他们充分认识到教学档案是学校开展教学研究的重要参考依据。是应对各类教学检査和评 估、提高办学管理水平的宝贵资料。

为了保障产学教育的质量, 建议充实产学教育教学档案的内容, 首先把高校与企业合 
作的意向书或者合同书列入归档范围。这样可以保证高校与企业的长期合作关系。同时稳 定产学合作教育的师资力量。其次增加专业实践教学教师的档案。此类档案应急记录实践 教师的学历、学位层次, 所学专业和原来就读的高校, 教学年龄, 教学特点和专长, 以便 让学生进行选择适合自己的实习指导教师。

\section{3 明晰各管理责任, 强化制度保障}

鉴于产学教育教学档案的管理跨度大影响档案的生成质量, 立档时间和归档时间, 造 成档案的管理混乱等问题。所以要明晰档案的管理责任。对于档案管理部门的角色进行明 确定位。学院领导是教学档案管理的总指挥。 ${ }^{[9]}$ 确定教研室和合作企业为产学合作教育档 案形成部门, 院系的教学管理办公室负责对于教学档案进行立卷工作, 并且负责整理装订 装盒, 移交到学校的档案馆。由档案馆负责档案的保管、提供借阅、查询等工作。

要保障产学合作教育档案的完整性、系统性和连续性, 必须完善教学档案的管理体制, 制定相应的管理制度、规范和工作流程。高校要依照 《中华人民共和国档案法》、《高等 学校档案管理办法》和《高等学校档案工作规范》等法律法规, 制定各项教学档案管 理的规章制度。 ${ }^{[10]}$ 只有完善的制度保障, 才会有高质量的产学合作教育档案的形成, 才能 保证此类档案的管理水平。

\section{4 提高产学合作教育档案的信息化水平}

随着计算机及网络多媒体的广泛应用, 产学合作教育档案数字化的趋势不可挡。因此 高校的管理者, 要与时俱进, 及时更新教学档案管理的硬件和软件, 不断提高档案的信息化管理水平。根据学校实际情 况, 给予教学管理部门、教师、和学生一定的权限, 适当地开设网络、在线咨询, 提供借 阅查询服务, 实现产学合作教育档案的社会服务功能及其价值最大化。

\section{5 结语}

产学合作教育教学档案是教学档案的重要组成部分, 建立保管好这类教学档案, 有利 于产学合作教育模式的深化发展。只有树立现代化的档案管理理念, 增强教学管理者和一 线教师的档案意识, 建立完善的产学合作教育教学档案的管理规章制度, 推进信息化进程, 才能让档案更好的服务于高校产学合作的发展。

\section{参考文献:}

[1] 张立昌, 栗洪武. 教学哲学 $[\mathrm{M}]$ 北京: 中国社会科学出版社。2009（8）

[2] 袁振国. . 当代教育学 [M] 北京: 教育科学出版社, 2005.257

[3] 刘璐. 基于教学档案袋的教师评价研究 [D] 上海, 上海师范大学 2013（4)：10-11

[4] 陈玲. 刘儒德. 当代教育心理学 [M] 北京: 北京师范人学出版社, 2007：84

[5] 陈霞. 教师专业发展的实效性研究 [M] 北京：北京大学出版社 2012.24

[6] 王占可. 高校教学档案管理的创新模式探究 [J]山西档案, 2014（2): 93

[7] 范丽娜、刘腾. 高校教学档案的价值与优化对策分析 [J] 南方论刊, 2014 (1): 104

[8] 陈爴. 加强学校教学档案收集工作之我见 [M] 档案管理理论与实践-浙江省基层档案工作者论文集, 2014

[9] 武玲娥. 高校院（系）教学档案管理模式初探——以宁夏大学政法学院为例 [J] 山西档案, 2014 (3): 96

[10] 卢宏伟. 浅析高校教学档案的形成与管理 [J] 北京档案, 2009 (5): 24 


\section{References:}

[1] Zhang Lichang, Li Hongwu. Teaching philosophy(Ms., China Social Science Press ,Beijing China)2009(8)

[2] Yuan Zhenguo. Contemporary Pedagogy(Ms., Education Science Press, Beijing China2005), p.257

[3] LiuLu, Research on Teacher Evaluation Based on Teaching Portfolio [D]. Shanghai Normal University, Shanghai, China),2013(4): p.10-11

[4] Chen Lin, Liu Lude. Contemporary Educational Psychology(Ms., Beijing Normal University Press, Beijing China2007) ,p.84

[5] Chen Xia, Research on the Effectiveness of Teachers' Professional Development, (Ms., Beijing University press, Beijing China2012),p24

[6] Wang Zhangke. "Research on the innovation mode of teaching archives management in Colleges and Universities" [J]. Shanxi Archives, No.2(2014)p.93(in Chinese)

[7] Fan Lina, Liu Teng "Analysis on the value and optimization of teaching archives in Colleges and Universities" [J]. Southern Journal No.1.1(2014) p.104(in Chinese)

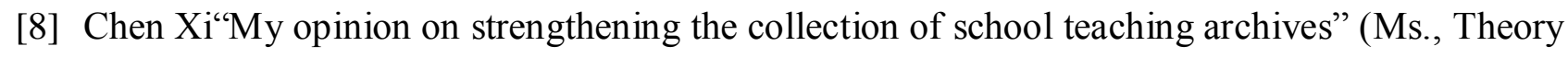
and practice of Archival Management - Zhejiang provincial archives workers, 2014)

[9] Wu Line. A preliminary study on the management model of teaching archives in Colleges and Universities -- Taking Ningxia University as an example [J]. Shanxi Archives, No.3 (2014)p.96 (in Chinese)

[10] Lu Hongwei. "Analysis on the formation and management of teaching archives in Colleges and Universities" [J]. Beijing Archives, NO.5(2009)p.24(in Chinese) 